A. K. CLARKE, M. J. JAMES, P. O'BRIEN, R. J. K. TAYLOR,* W. P. UNSWORTH* (UNIVERSITY OF YORK, UK)

Silica-Supported Silver Nitrate as a Highly Active Dearomatizing Spirocyclization Catalyst: Synergistic Alkyne Activation by Silver Nanoparticles and Silica

Angew. Chem. Int. Ed. 2016, 55, 13798-13802.

\section{Spirocyclization of Alkyne-Tethered Aromatics with Silver Nitrate/Silica}

Indoles:<smiles>[H][R]c1[nH]c2ccccc2c1C(C)C(=O)C#CC</smiles>

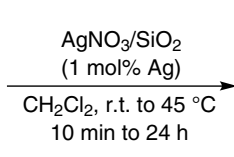<smiles>CCC1=Nc2ccccc2C12CC(=O)C=C2[Tl]</smiles>
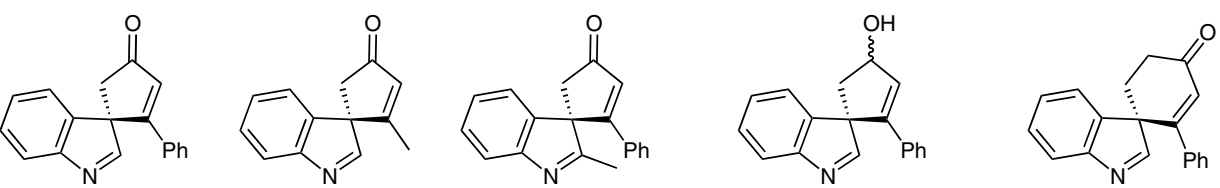

Gategory

Polymer-Supported

Synthesis

Key words

silver nitrate

silica gel

dearomatization

spirocyclization

heterogeneous

catalysis

spiro compounds

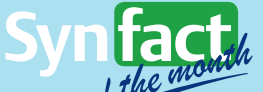
of the

$30 \mathrm{~min}$, r.t., $98 \%$ yield $10 \mathrm{~min}$, r.t., $94 \%$ yield $35 \mathrm{~min}$, r.t., $95 \%$ yield $24 \mathrm{~h}$, r.t., $100 \%$ yield $(\mathrm{dr}=1: 0.6) \quad 24 \mathrm{~h}, 45{ }^{\circ} \mathrm{C}, 100 \%$ yield Phenols:<smiles>[R]C#CC(=O)Cc1ccc(O)c([R])c1</smiles>

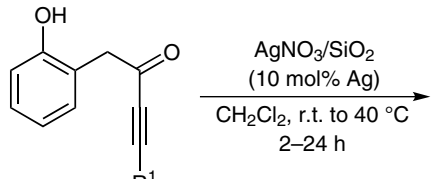<smiles>[R]C1=CC2(C=CC1=O)CC(=O)C=C2[R]</smiles><smiles>O=C1CCC2(C=CC=CC2=O)C(=O)C1</smiles><smiles>[R7]C1=C[C@]2(C=CC1=O)CC(=O)C=C2[R]([H])[H]</smiles>

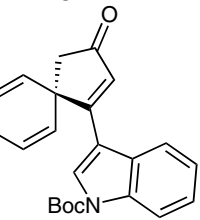<smiles>O=C1C=C(c2ccccc2)C2(O)C=CC=CC12</smiles><smiles>O=C1C=CC=C2C(C3CC3)=CC(=O)C12</smiles>

7 h, r.t., $99 \%$ yield 2 h, r.t., $90 \%$ yield 2 h, r.t., $96 \%$ yield

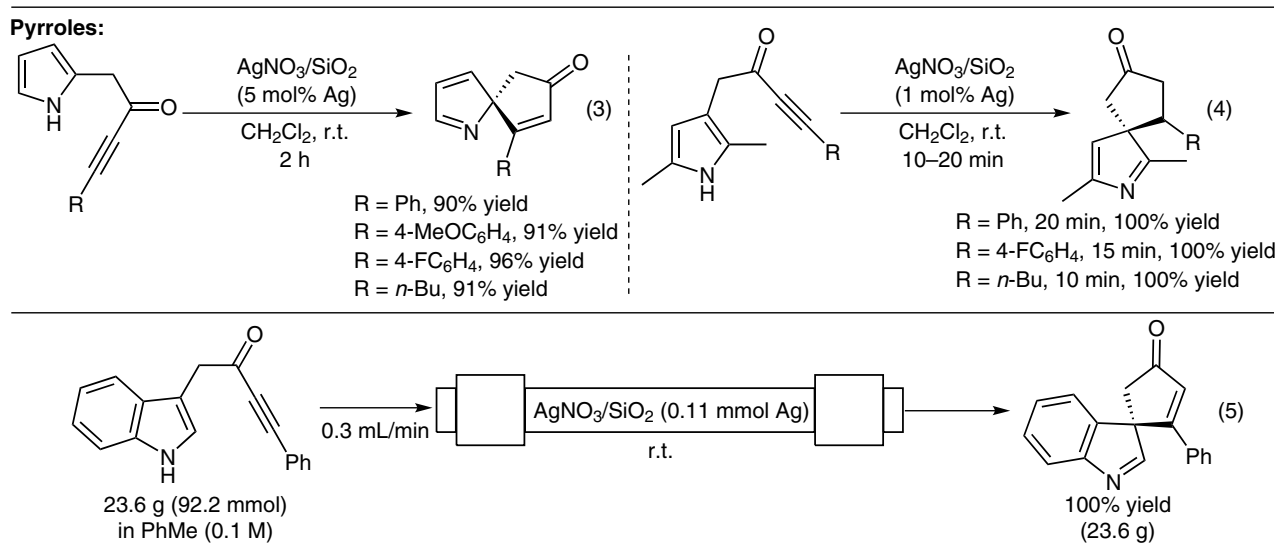

Significance: Silica-supported silver nitrate $\left(\mathrm{AgNO}_{3} / \mathrm{SiO}_{2}\right)$ catalyzed the dearomatizing spirocyclization of alkyne-tethered aromatics to give the corresponding spirocycles in $86-100 \%$ yield (eqs. 1-4).
Comment: The continuous-flow reaction of 1 (1H-indol-3-yl)-4-phenylbut-3-yn-2-one on a column of $\mathrm{AgNO}_{3} / \mathrm{SiO}_{2}$ gave 5-phenyl-3H-spiro[cyclopent-4-ene-1,3'-indol]-3-one in quantitative yield (eq. 5).

sYNFACTS Contributors: Yasuhiro Uozumi, Go Hamasaka

Synfacts 2017, 13(01), 0099 Published online: 19.12.2016

Dol: 10.1055/s-0036-1589770; Reg-No.: Y16216SF 